\title{
Comparison of Macroeconomic Developments in Ten Scenarios of Energy System Transformation in Germany - National and Regional Results
}

Philip Ulrich ( $\square$ ulrich@gws-os.com )

Gesellschaft fuer Wirtschaftliche Strukturforschung https://orcid.org/0000-0002-1029-4546

\section{Tobias Naegler}

German Aerospace Center (DLR), Institute of Networked Energy Systems

\section{Lisa Becker}

Institute of Economic Structures Research (GWS)

Ulrike Lehr

Institute of Economic Structures Research (GWS)

\section{Sonja Simon}

German Aerospace Center (DLR) Institute of Networked Energy Systems

\section{Claudia Sutardhio}

University of Freiburg Department of Sustainable Systems Engineering (INATECH)

\section{Anke Weidlich}

University of Freiburg Department of Sustainable Systems Engineering (INATECH)

\section{Original article}

Keywords: Energy scenario, macroeconomic modeling, energy system modeling, impact assessment, regional impacts, social indicators, sustainability, renewable energy, hydrogen strategies

Posted Date: August 19th, 2021

DOl: https://doi.org/10.21203/rs.3.rs-812291/v1

License: (1) (i) This work is licensed under a Creative Commons Attribution 4.0 International License. Read Full License 


\section{Abstract}

\section{Background}

Many different strategies have already been proposed for the transformation of the energy system in Germany. To evaluate their sustainability, it is necessary to analyze their macroeconomic and distributional effects. An approach to do this in an integrated and consistent framework is presented here.

\section{Methods}

The comparison of ten energy transition scenarios with emission reduction targets by 2050 of $80 \%$ or $95 \%$, respectively, allows the evaluation across a broad range of different strategies with respect to the future technology and energy carrier mix. For this purpose, an energy system model and a macroeconometric model are combined, thus re-modeling the unified scenarios. An important extension of the model was concerned with the integration of synthetic fuels into the energy-economy model. One focus besides the overall macroeconomic assessment is the regional analysis. For this purpose, own assumptions on the regional distribution of the expansion of renewable energies were developed.

Results

The effects on gross domestic product (GDP) and employment are similar in average from 2030 to 2050 between the scenarios, with most of the more ambitious scenarios showing slightly higher results for the socioeconomic variables. Sectorally, employment in the construction sector shows the largest effects in most scenarios, while in the energy sector employment is lower in scenarios with high energy imports. At the regional level, the differences between scenarios are larger than at national level. There is no clear or stable regional pattern of relative loss and profit from very ambitious transformation, as not only RE expansion varies and hydrogen strategies enter the scene approaching 2050.

\section{Conclusions}

From the relatively small differences between the scenarios it can be concluded that, from a macroeconomic perspective, it is not decisive for the overall economy which (supply side) strategy is chosen for the transformation of the energy system. More effort needs to be put into improving assumptions and modeling approaches related to strategies for achieving the final $20 \% \mathrm{CO} 2$ reduction, for example the increasing use of hydrogen.

\section{Introduction}

A variety of studies describe development paths for achieving large reductions in greenhouse gas emissions in the short to medium term, and climate neutrality in the long term. At a global level, this has been recently compared by IRENA (Gielen et al. 2021). The findings are that energy transition scenarios converge in the main strategies, but diverge in some of the details. The role of renewable energy under the 
different scenarios and the need for electrification seem to be mainly agreed upon across international scenarios, the role of bioenergy, carbon capture and storage (CCS) and carbon capture and utilization (CCU) less so (Fragkos et al. 2020). For Germany, the picture is similar, with certain technologies and strategies planned to a greater extent in more ambitious scenarios than in the case of lower emission reduction targets (Samadi et al. 2018). Scenarios achieving the targets in 2050 do so under different technology pathways, speeds, and energy mixes (Naegler et al. (submitted)). While the technical feasibility of the energy transition is given, the challenge is seen in the natural limits of resource potentials, especially biomass (Hansen et al. 2019).

For Germany, single scenario analyses comparing more ambitious scenarios to less ambitious businessas-usual (BAU) cases or a counterfactual scenario often show positive effects for gross domestic product (GDP) and employment (Sievers et al. 2019, Lutz et al. 2018, Lutz et al. 2021a). At the EU level, transformation scenarios are also assessed in terms of their socioeconomic consequences by soft linking energy system models with macroeconomic models (Fragkos et al. 2017, Vrontisi et al. 2019). In the study by Fragkos et al. (2017), there are some small negative effects on GDP, while employment is slightly higher than in the reference development. Vrontisi et al. (2019) point out that the direction of economic effects varies depending on the political conditions: Thus, negative economic effects arise for the EU member states when asymmetric ambitions of climate policies exist. In contrast, economic benefits in the EU can be achieved if there are globally coordinated efforts to achieve the Paris climate goals. An integrated assessment of EU-wide energy transition pathways provides a combined evaluation of environmental and economic aspects. In this way, Nieto et al. (2020) analyze a large number of scenarios concluding that only a post-growth scenario can achieve emissions reduction targets without negative impacts on employment.

The scenario analyses differ by the economic model selected, analytical framework and the underlying economic theory. In addition, the different underlying framework assumptions and data complicate a comparison between the scenarios. A complete harmonization of techno-economic quantities is hampered by large differences in the structural representation and the numerical parameterization of technologies (Krey et al. 2019).

While sustainability analysis needs to go beyond the mere megawatt and cost debate and increasingly focuses on coupling of models (Naegler et al. 2021, Rocco et al. 2018), the socio-economic dimension is featuring highly, also in the just transition debate. Next to the macroeconomic indicators such as GDP, its components and employment, structural change and distribution aspects increasingly enter the public debate (see e.g. Oei et al. 2020, Bach et al. 2021). Social aspects need to be addressed to make the energy transition just and inclusive and increase acceptance in the population.

To contribute to this discussion, we compare ten different energy transformation strategies, all assuming a reduction of $\mathrm{CO}_{2}$ emissions by at least $80 \%$ relative to 1990 in 2050 . The methodological challenge is to harmonize assumptions across different works in the literature, to enable this comparison across scenarios and provide meaningful differences. The underlying assumption is that the energy transition as 
such has been decided (German Federal Government 2021, European Commission 2021), and the sustainability analysis may focus at comparing the different pathways to attain the targets. Therefore, the technology mix in the future energy system is of particular interest. There are strategies with a focus on synthetic fuels and ones with a particularly large amount of renewable electricity and storage. The expansion of renewable energy and the importance of synthetic fuels varies, as does the role of energy imports. How do macroeconomic effects differ between alternate technological transition strategies with similar GHG reduction targets? To answer this question, we apply the macroeconometric simulation model PANTA RHEl which is the environmentally extended version of the simulation and forecasting model INFORGE (Maier, Mönnig, Zika 2015). Besides the comprehensive economic core, the energy sector and emissions as well as transport and housing are modeled in detail. This paper thus presents the results of the simulation of the German economy under ten energy transition scenarios. The output of this analysis is a set of economic indicators, which can be used in further sustainability assessments of energy transitions.

Social and distributional aspect are often blurred if the analysis stops at the national level. Several studies assess regional effects of an energy system transformation in Germany. Sievers et al. (2019) compare an energy transition scenario with a reference development until 2030 . They conclude that the eastern federal states and generally coastal states would have the highest positive deviations in relative terms. Changes in the electricity market are the main reason for the regional differences. Ulrich et al. (2018) use the scenarios for the German energy transition developed in Lutz et al. (2018) for a modelbased regional analysis until 2040. Here, too, many German states in the north and east show particularly high positive deviations. A systematic comparison between different ambitious transformation paths until 2050 has not yet been undertaken. In studies on the impacts of an energy transition, regional distribution aspects at the subnational level too often are ignored and not addressed. To bridge this gap, a modeling framework was developed, which allows an evaluation of long-term economic effects on the level of 13 regions. We particularly address which regional effects and regional differences can be expected for selected transformation strategies. The results contribute to the debate on just transition policies and provide valuable quantitative input for decision makers and regional stakeholders alike.

The paper starts in Sect. 2 with a description of the energy system and the macroeconomic modeling and how the models interact. In addition, the method of regionalization is outlined. The results are presented in Sect. 3: After showing the results of the energy system modeling (Sect. 3.1) and the macroeconomic effects (Sect. 3.2), the paper turns to the regional dimension of impacts of an energy transition (Sect. 3.3). At the end, based on the obtained findings, the conclusions are drawn in Sect. 4.

\section{Models And Methods}

To answer the questions outlined above, a combination of different models and data compilations has been employed (Fig. 1). The energy system model translates scenarios from the literature to a comparable data set, by harmonizing across assumptions of GDP, labor force, population, the level of energy efficiency and other indicators enabling a ceteris paribus comparison where only the characteristic 
elements of each scenario drive results. These harmonized energy system scenarios feed the macroeconomic assessment with the model PANTA RHEI. To perform regional analyses, key variables of the harmonized scenarios need to be regionalized using selected indicators. These regionalized scenarios enable the subnational analysis of value creation and jobs in regional model coupled with the national macroeconomic model.

\subsection{Techno-economic energy system modelling}

Macro-economic impacts of national transformation strategies are based on scenario results from the harmonized re-modelling of different published transition scenarios for Germany (Lutz et al. 2018, Pfluger et al. 2017, Nitsch et al. 2012, Repenning et al. 2015, Henning and Palzer 2015, Nitsch 2014, Günther et al. 2017, Klein et al. 2017, Bründlinger et al. 2018). The scenarios describe the transformation of the entire energy system (electricity, heat, transport) in Germany up to 2050. Details on the selection process can be found in Naegler et al. 2021, a table of the underlying original studies in Supplement 1. Scenarios I- V describe moderately ambitious strategies to reduce direct energy-related $\mathrm{CO}_{2}$ emissions by ca. $80 \%$ until 2050 , whereas the highly ambitious scenarios VI X reach an emission reduction of ca. $95 \%$. Sectorspecific defossilization strategies were identified from the original studies, i.e., market shares of climatefriendly technologies in the end-use and conversion sectors. Subsequently, these supply-side strategies were set as boundary conditions for a harmonized remodeling of the scenarios: Drivers such as development path for the economy (exports), population, the development of useful energy demand and transport services etc. were held identical in all remodeled scenarios. In this way, the essence of the technical strategies of the original studies can be preserved. At the same time, the different studies are made comparable, as different boundary conditions are harmonized and biases between the scenarios due to different boundary conditions are avoided.

The energy system model (accounting framework) MESAP (Schlenzig 1999, Pregger et al. 2020) and the electricity market simulation model flexABLE (Qussous et al. 2019) were used for the re-modeling. While MESAP calculates complete annual energy balances for Germany for the conversion and end-use sectors, flexABLE uses MESAP results to calculate capacity factors and installed capacities of flexible power generators, power storages, and electrolyzers. In the next step, MESAP integrates the flexABLE results and calculates annual gross new and decommissioned capacities for all relevant system technologies (including cars and trucks).

Finally, economic indicators such as the annual investments in new technologies, capital, operating and maintenance costs resulting from new installations and existing plants, levelized costs of electricity, import quotas, and total system costs, are determined and exported to the macroeconomic model (see Sect. 2.3) Note that for the transport sector, only fuel costs, but no capital costs are considered. More details on the re-modelling of the scenarios and the coupling between energy system models and the macro-economic model can be found in Naegler et al. 2021. 
Energy system modelling results were used as boundary conditions for the macroeconomic calculations with PANTA RHEI. The framework assumptions are the same for all scenarios, since the consequences of different energy systems and not, for example, different population developments are analyzed. To model the different possible transformation pathways, scenario-specific assumptions are made that characterize the respective energy system. In addition to energy variables, economic variables such as investments in the expansion of renewable energy technologies are decisive for this. These inputs from MESAP are exogenously included into PANTA RHEl, placing the energy system part in a macroeconomic context.

\subsection{Regional distribution}

The regional distribution of environmental, social and economic impacts of an energy scenario is relevant for a sustainability assessment, because larger regional inequalities are usually not preferred, and a good regional balance of effects is associated with a just transition. Although political questions of equity and balancing of interests are related to this, these assumptions are not integrated and discussed in the remodeled scenarios. Therefore, an own set of indicators was developed to derive different distribution keys for the expansion of renewable energies. The regional level modelled are the federal states. Distribution keys and evaluation were based on 13 regions, as the three city states Berlin, Hamburg and Bremen were merged with respective territorial states Brandenburg, Schleswig-Holstein and Lower Saxony.

For renewable power sources which face a small expansion in all scenarios, such as biomass, hydro and geothermal energy, expansion was allocated according to the current distribution as considered in the model, based on data from the national renewable energy agency in Germany (AEE 2021). The capacity of PV and wind for each year up to 2050 and in each of the federal states results from the respective existing capacity and the new installation. Thus, the model applies the current distribution of capacities based on (AEE 2021) up to 2019, consistent with the other renewables. New wind offshore installations are allocated to among the three coastal regions Niedersachsen-Bremen, Schleswig-Holstein-Hamburg and Mecklenburg-Vorpommern.

For wind onshore and PV, which will see the largest expansion in all the considered scenarios, three different regionalization approaches are considered for both capacity and investments from 2020 onwards, to allow for a sensitivity analysis. The different approaches are selected to represent technical criteria, current planning strategy and social criteria separately. Investments are solely based on capacity expansion, which leads to a slight inaccuracy, neglecting repowering. The three selected distribution criteria are:

1. Distribution according to the technical potentials for respective technologies

2. Distribution according to the National Grid Development Plan for power

3. Distribution according to social criteria to include the aspect of promoting structurally weak regions 
The distribution according to the technical potential considers the availability of solar and wind sources. The total technical potentials are taken from the national renewable energy agency in Germany (AEE 2021). We calculate shares of the national potential of installable capacity for each region (Table 1). Federal states with a high share of the potential record an equally high share of new installations per year. This target distribution in $\mathbf{2 0 5 0}$ gradually evolves from the current distribution of existing capacity.

Table 1

Distribution of PV and wind potentials in Germany based on (AEE 2021)

\begin{tabular}{|lll|}
\hline Capacity potential & Wind onshore & PV \\
\hline Baden-Württemberg & $11 \%$ & $10 \%$ \\
\hline Bayern & $20 \%$ & $8 \%$ \\
\hline Brandenburg \&Berlin & $7 \%$ & $13 \%$ \\
\hline Hessen & $7 \%$ & $6 \%$ \\
\hline Mecklenburg-Vorpommern & $6 \%$ & $13 \%$ \\
\hline Niedersachsen \& Bremen & $14 \%$ & $14 \%$ \\
\hline Nordrhein-Westfalen & $10 \%$ & $15 \%$ \\
\hline Rheinland-Pfalz & $6 \%$ & $6 \%$ \\
\hline Saarland & $1 \%$ & $1 \%$ \\
\hline Sachsen & $5 \%$ & $4 \%$ \\
\hline Sachsen-Anhalt & $4 \%$ & $4 \%$ \\
\hline Schleswig-Holstein \& Hamburg & $6 \%$ & $5 \%$ \\
\hline Thüringen & $4 \%$ & $3 \%$ \\
\hline
\end{tabular}

The distribution of PV and wind onshore according to the National Grid Development Plan for power (GRDP) was adapted from the German transmission system operators (Übertragungsnetzbetreiber 2019). The new installation of PV and wind onshore was calculated from the difference between the total installation in the target years (in the study year 2030 and 2035) and the existing installation (for PV in 2017, for wind onshore in 2016). According to the study, the shares of each technology per state hardly change over the years despite growing capacities. For this reason, it is assumed that the shares of new installations per state in 2035 remain the same until 2050.

The distribution according to social criteria is the result of a combination of six indicators. The number of unemployed is the primary distribution, which is multiplied by a factor resulting from the combination of normalized individual indicators: Labor productivity (producing industries), subsidies paid from the structural funds, employment in lignite coal mining, the share of the construction sector in the region and 
the gross employment from renewable energy expansion. The latter distinguishes existing employment in the wind and PV sectors, to generate specific distributions. Each indicator has a weight to reflect the content meaning and value ranges.

Table 2

Indicators combined for the distribution by social criteria, specific weights and data sources

\begin{tabular}{|lll|}
\hline Indicator & Weight & Source \\
\hline Number of unemployed & $\begin{array}{l}\text { Primary } \\
\text { key }\end{array}$ & Federal Employment Agency \\
\hline Labor productivity & 0.25 & National accounts of the federal states \\
\hline Subsidies paid from the structural funds & 0.2 & $\begin{array}{l}\text { Federal Institute for Research on Building, } \\
\text { Urban Affairs and Spatial development } \\
\text { (2018) }\end{array}$ \\
\hline Employees in lignite coal mining & 0.15 & $\begin{array}{l}\text { Federal Ministry for Economic Affairs and } \\
\text { Energy (2018) }\end{array}$ \\
\hline Share of construction sector in region & 0.2 & National accounts of the federal states \\
\hline $\begin{array}{l}\text { Gross employment from renewable energy } \\
\text { expansion 2016 (Wind energy or PV) }\end{array}$ & 0.2 & Ulrich and Lehr 2018 \\
\hline
\end{tabular}

Figure 2 shows the distribution of new installed capacities according to the three distribution keys. The shares of new installations for onshore wind energy differ more from distribution of the population than those for PV. It becomes apparent that the GRDP distribution in general is very similar to that according to natural potentials. The distribution according to social criteria is a more contrasting assumption. Note that fossil-fuel power plant capacity decommissioning was not performed using region-specific assumptions. The deconstruction is proportional to the region-specific inventory in the base year.

\subsection{PANTA RHEI}

For a comprehensive sustainability assessment of energy systems, the economic dimension is an important element. Securing jobs, maintaining the investment capability of companies and the government, and the long-term stability of the economy characterize a sustainable development from the economic perspective. To determine the macroeconomic effects of a transformation of the energy system, a model is required that approximately represents the real conditions and relationships. The energy system is strongly embedded in almost all areas of the economy, which means that the impacts triggered by a transformation affect the economy at many points. In this context, the different effects cannot be calculated separately, but the feedback and second round effects as well as interactions must be included in a consistent framework of the entire economy with all its actors.

The analysis is based on results from the macro-econometric input-output model PANTA RHEl, which was most recently used to estimate the socio-economic effects of the German Climate Change Act and alternative target paths (Lutz et al. 2021a) and to model rebound effects in the energy consumption of 
industries (Lutz et al. 2021b). The model's philosophy and properties as well as its applications are summarized in Lehr and Lutz (2020, pp 476-477). A short overview of the model can be found in Supplement 2.

The macroeconomic core of the energy-economy model PANTA RHEl comprises national accounts and input-output tables (Destatis 2021), leading to disaggregation to at least 63 sectors or commodity groups. Econometric estimation of behavioral equations determines the model's parameters. The model is solved annually in an iterative process and does not emphasize either the supply or demand side (Maier et al. 2015). The comprehensive economic core is complemented by energy and environment modules. The energy module contains energy balances (AGEB 2021a), satellite balances for renewable energy (AGEB 2021b), and energy prices (e.g. BMWi 2021), as well as energy specific behavioral equations. New energy sources such as power-to-X technologies are not yet explicitly contained in the statistics, but highly relevant for future scenarios. Therefore, the data structures must be extended for modeling future developments. A proposal for integrating these energy sources into energy balances can be found in Lehr et al. (2020).

The energy module shows the multidimensional linkage with the economic core through trade, investment, and prices. To reflect the particular structure of renewable energy and energy efficiency investment, which is crucial for any energy transition, technology specific investment converters are used. These cost structures are based on surveys and they use the economic sector classification NACE (Destatis 2008) applied throughout the model (O'Sullivan and Edler 2020, Lehr et al. 2012).

\subsection{Regional modelling}

Often, the macroeconomic effects determined by comparing scenarios are such that aggregated indicators show only minor deviations. At the regional level, however, the effects can be significantly larger. The LÄNDER model is used to analyze and project structural change at the level of the 16 federal states of Germany (see Ulrich an Wolter 2013). It is directly linked to the national model PANTA RHEI and uses the sectoral results for value added and employment determined there at the regional level. The model enables the analysis of different simulation scenarios at the federal state level. In the modeling, the regional labor markets (number of employed persons and employees), gross value added and indicators of wage and salary development are modelled at the level of 37 economic sectors. In addition, the effects of a selection of intermediate inputs are shown at the regional level. In the version used to analyze the energy system transformations further links between the regional economic and energy system were established (Ulrich et al. 2018).

The comprehensive model thus enables the analysis of regional effects of different transformation paths and considers the entire economy of the federal states with their specific structures. However, such an analysis requires explicit assumptions on the design of the transformation in the regional context. The default configuration for the comparison of developments between the ten scenarios is the distribution along the natural potentials. For the scenarios I and VI distributional effects were examined using the alternative regional distribution keys, namely 'GRDP' and 'social indicators'. 
A large share of the value added created from the investment in the expansion of renewable energies is generated by the production of the systems in Germany. Depending on the technology, a substantial share of the direct and indirect demand effects is also attributable to on-site installation. Thus, the demand associated with the investment is significantly redistributed spatially compared to a proportional allocation. Based on the findings in Ulrich and Lehr $(2018,2013)$ and the model used there, we analyze the effects of this redistribution in a sensitivity. The used model - here referred to as hyBRID - is an input-output model with an integrated spatial reallocation algorithm (see Ulrich et al. 2012, Ulrich 2013). In addition to techno-economic data sets, detailed information on the production locations of the RE sector as well as specific structures of the 16 federal states are stored as essential bases of the model. In this model framework scenario VI was compared with scenario I and deviations were implemented in the composite model PANTA RHEI-LÄNDER. The results - the redistribution by additional regional demand from investment - is integrated in the synthesis of regional impacts in Sect. 3.3. It reflects the potential additional effect from the specific structure of the German RE manufacturing market in the present.

\section{Results}

\subsection{Outline of the energy system transformations}

In the following section, we summarize some central results from the scenario modeling. A detailed documentation of the results can be found in the supplementary material.

Figure 3 (left panel) shows the gross power demand in 2050 in the different scenarios, differentiated by application. It can be seen that the gross power demand in the moderately ambitious scenarios I-V (between 528 and 598 TWh in 2050) is similar to today's power demand (577 TWh in 2020), although new applications - in particular road transport and power-to-heat, but also synthetic fuels and gases (P2X) - contribute increasingly to the demand. The highly ambitious scenarios SCEN VI-IX are characterized by a significantly higher gross power demand (between 924 TWh in SCEN VI and almost 1,700 TWh in SCEN X), mainly due to a higher demand for synthetic fuels and gases (P2X), but partly also due to a higher degree of direct electrification of road transport and heat. In SCEN VIII and SCEN X, a significant share of this electricity is assumed to be imported to Germany.

Figure 3 (right panel) shows the resulting capacities for power generation, which broadly follow the power demand. PV, wind onshore and wind offshore provide the backbone of the power generation, but the scenarios differ significantly with respect to the share of these technologies in total installed power generation capacity. Estimates for the installed capacity of PV range between $64 \mathrm{GW}$ and $913 \mathrm{GW}$, for wind onshore between $81 \mathrm{GW}$ and $267 \mathrm{GW}$, and wind offshore between $26 \mathrm{GW}$ and $114 \mathrm{GW}$. The import of electricity and $\mathrm{P} 2 \mathrm{X}$ requires significant installed capacities abroad in some of the scenarios (particularly pronounced in SCEN VIII and SCEN X).

Figure 4 summarizes the energy system model output which either has been used as input for the macroeconomic modelling or for the assessment of macroeconomic model results below. Panel (a) 
shows the development of gross energy imports (fossil fuels, P2X, electricity, ...), which decreases in all scenarios from today's level of ca. 10,000 PJ/a to values between 1,350 PJ and more than 4,500 PJ. Panel (c) shows the decrease of direct energy related $\mathrm{CO}_{2}$ emissions by ca. $80 \%$ (SCEN I-V) and by ca. 95\% (SCEN VI-X) relative to 1990. In panel (e) we see the increase in power demand for P2X generation (domestic and abroad) in all scenarios (compare with Fig. 3). Panel (b) shows the annual capital costs (annuities) resulting from the investments necessary to achieve the different transformation paths. Panel (d) in Fig. 4 shows the annual operation and maintenance (O\&M) costs, and panel ( $f$ ) the total system costs, i.e. the sum of capital and O\&M costs. Here it can be seen that the different transformation strategies and $\mathrm{CO}_{2}$ emission reduction targets result not only in different power demand and technology portfolios, as can be seen in Fig. 3 and Fig. 4, but also in significantly different system costs. The highly ambitious scenarios SCEN VI-X tend to show significantly higher system costs over most of the transformation paths than the moderately ambitious scenarios SCEN I-V, reflecting higher investment due to a faster and deeper transformation, but also higher O\&M costs than the moderately ambitious scenarios. A detailed documentation of the scenario results can be found in the supplementary material provided on the project homepage.

\subsection{Results from the national macroeconomic analysis}

Various indicators have been selected for the evaluation of macroeconomic results of the model. GDP, despite being criticized as being too broad and unilateral, still serves as the indicator of choice for economic development and growth. Investment indicates future returns and wealth, it also shows how much effort is needed to initiate and drive the energy transition. Investment drives production, be it domestically or imported. When produced domestically, additional production drives value added and leads to more value and employment in the respective sectors. Employment provides livelihoods and contributes to people's wellbeing. Additional income feeds back to the economy as additional consumption, thus increasing the multiplier effects. In an open economy, additional activities also spur imports, thus lowering the overall result. Over time, investment will be recovered by higher costs. Also, substitution of domestically produced energy by imports affects prices. Policies to drive the energy transition, such as carbon pricing, put additional pressure on prices. The ten scenarios compared contain different levels and pathways for the above, leading to different outcomes of the economic simulation model runs.

The simulation results for a selection of key indicators are shown in Fig. 5. When comparing the ten scenarios, the first observation is that the macroeconomic variables are very close to each other on average from 2030 to 2050. Most of the more ambitious scenarios VI to X show higher levels of GDP and employment at the end of the projection period than the scenarios aiming at an $80 \%$ GHG reduction compared to 1990 (I to V). Investment is generally higher in the more ambitious scenarios, resulting in more positive economic effects. Scenarios seven and nine, for example, assume a high expansion of offshore wind and photovoltaics, respectively, which tend to be more employment-intensive than onshore wind. However, the development of GDP also depends on the development of price levels, operating and 
maintenance costs, and imports along the path. For example, the comparatively low employment in the very ambitious scenario $X$ is the result of an investment level comparable to that of an $80 \%$ scenario and high energy imports. In scenario seven, macroeconomic imports and the price level develop dynamically. However, domestic demand impulses dominate, and less energy is imported. Overall, the small differences between the alternative pathways can be considered plausible. All scenarios represent a transformation, with investments in new technologies and an energy mix that is fundamentally different from that of the past. A comparison with a BAU scenario, an analysis that has been done more frequently in the past, shows significantly larger differences in the long term. It should also be remembered that final energy consumption is roughly the same in all scenarios, so that no scenario can set itself apart with import savings, for example. More ambitious scenarios have rather high overall imports. Strong price developments are not necessarily a bad precondition. Scenarios with high transformation-related demand usually reach a higher price level by 2050. Constellations in which high prices meet rather low employment are problematic. Therefore, Scenario VIII does not have much more favorable characteristics than the less ambitious Scenario V.

Of particular importance is how the individual economic sectors develop, and which economic sectors benefit from the transformation, and which may be disadvantaged by 2050 . This analysis is carried out based on employment in 2050. Typically, an analysis of differences between scenarios is performed to better illustrate effects. To better highlight the differences, we selected one of the $80 \%$ scenarios (Scenario I) as a reference and compare the simulation results of the other nine scenarios to this reference scenario. Relative differences in percent illustrate the magnitude of a scenario's impact when all other factors are held equal (ceteris paribus assumption). Relative differences allow us to see whether the impact on a particular sector of the economy is large or small compared to developments in Scenario I.

The scenarios have different effects on employment in the respective sectors. Figure 6 shows the relative differences in employment in seven sectors (groups of ISIC-rev4 sections). Construction shows the largest positive effects, especially in four out of five very ambitious scenarios. Investment leads to higher demand, which is most evident in construction, but also in business services. In the energy sector and industry, the effects are different but also small. As a rule, this sector cannot sustainably benefit from the additional demand in the very ambitious scenarios, which is mainly due to the stronger price development. Scenario $X$, as a special case, has lower employment compared to the reference scenario, as it relies mainly on hydrogen imports, with little investment in domestic infrastructure or technology. In particular, scenarios with high energy imports (see below) lead to reduced employment in the energy sector.

Note that total employment will decline in all scenarios by 2050 due to demographic change. The number of people in the labor force will decrease accordingly. Also, the ceteris paribus assumption includes the general structural shift toward services in all scenarios.

The integrated approach calls for these macroeconomic development results to be compared with indicators representing the energy system characteristics. In Fig. 7 four indicators from the energy system 
remodelling were chosen to be compared with the GDP indicator. Graph (a) clearly shows the cluster of ambitious and very ambitious scenario regarding the $\mathrm{CO}_{2}$ reduction until 2050. Further, four of the five scenarios with more than $90 \%$ energy-related $\mathrm{CO}_{2}$ reduction show a higher GDP than all less ambitious scenarios. Graph (b) illustrates that most of the ambitious scenarios have significantly higher system costs. Overall, the realizations of GDP at the end of the projection period increase with the system costs. Again, scenario $X$ is the least advantageous here. Scenario 6 attains a high GDP with rather low system costs. In contrast to total economic imports (of all goods), gross energy imports in physical units show a different relationship with economic output. The ambitious scenarios save large amounts of imports for fossil fuels. Therefore, low gross imports are accompanied by high GDP realizations here (Graph (c)). However, scenario 7 has very high energy imports and still achieves the highest GDP, as investment is particularly high. Technologies for the use of hydrogen and synthetic fuels are needed to varying degrees. For the Scenarios 8, 9 and 10, the demand for hydrogen and synthetic fuels reaches amounts of $1300 \mathrm{PJ}$ and more by 2050. In nearly all very ambitious scenarios these new energy carriers play a substantial role, which does not have a negative impact on the economic outlook. It should be mentioned, however, that due to a lack of data, it had to be assumed that the prices of synthetic fuels do not differ fundamentally in level and development from comparable conventional energy sources. A striking finding is that a reduction of greenhouse gas emissions by another $15 \%$ since 1990 compared to the $80 \%$ scenarios significantly changes the macroeconomic developments. The less ambitious scenarios hardly differ one from another, while the $95 \%$ scenarios show a wider range of developments until 2050.

\subsection{Regional results}

The regions show different levels of GDP and employment across the scenarios by 2050. In fact, a deviation analysis from a reference (here scenario I) shows that regional GDP can be lower, although a higher GDP is achieved for Germany as a whole. For example, not all German states can benefit from a very ambitious scenario in a regional comparison. Attributes were selected for clustering to summarize the results for ten scenarios and 13 regions. One attribute is the standard deviation of the regional share across the scenarios. Furthermore, the largest and smallest regional shares were identified for each of the federal states to assign them to the group of ambitious and very ambitious scenarios. The shares in employment in 2045 were evaluated, since the differences in this year are comparatively high. This is due to the fact that both the national level of investment and the respective differences between the scenarios are high in that period. In general, at the end of the projection period, structural developments as longterm macroeconomic adjustments to the transformation paths are more likely to occur.

Figure 8 shows how the regional distribution of employment is affected throughout the transformation scenarios. For example, the regional share of Lower Saxony-Bremen in Germany varies across the scenarios in 2045 between 9.08 and 9.18 percent. If the average share is attained in the ambitious scenarios ( $\mathrm{VI}$ to $\mathrm{X})$, they are declared to have relatively high profit from a zero-carbon transformation. These regions for 2045 are located in nearly every part of the country. They only do not occur in the southwest. The pattern changes slightly between 2040 and 2050, as northern federal states are 
increasingly unlikely to belong to the group of regions for which a very ambitious transformation path is particularly advantageous. The sensitivity to changes in the technology mix is defined by the standard deviation of regional shares across scenarios. If the value is above the highest tercile, the sensitivity is considered high. In 2045 the uncertainty is highest in Lower Saxony-Bremen and Northrine Westfalia, but also in Hesse, Baden-Württemberg, Saxony and Brandenburg-Berlin, the economic development very dependent on the transformation strategy in detail. The results show that familiar patterns of positive affect dissipate when only different, long-term transformation strategies are compared. All scenarios assume a substantial expansion of RE-facilities, so that other changes in the energy system and in the whole economy come into impact, especially the evolving hydrogen strategies from 2040 and later. None of the scenarios leaves individual regions behind in terms of development. However, there are individual scenarios that are highly polarizing, such as Scenario VII and Scenario V, and especially by 2050 Scenario IX

The structural characteristics in the major regions, those of the energy industry but also across all sectors, are decisive for the regional effects. An important factor is certainly the focus of RE use in the scenarios. Scenarios 6 and 7 focus on the expansion of wind energy. Here, those federal states achieve the highest shares that have a focus on wind energy - today and according to the distribution keys for the future expansion (the north). Scenario 9 in contrast achieves the highest PV expansion and is in favor of regions like Baden-Württemberg and Saxony. A major structural effect is that in the East-German regions, construction has a high weight in regional employment. In scenarios with high investment, the construction sector benefits particularly strongly, which is less noticeable in regions with a disproportional low weight of this sector.

Focusing on Scenario 1 and 6, the analyses were enhanced. The results are summarized in Fig. 9. First, the effects of the alternative regional distribution keys for the expansion of renewable energies were examined as sensitivities. The alternative, regional distribution keys - 'Grid Development Plan' (GRDP) and 'Social indicators' - for the expansion of renewable energies reinforce the already described gradient from southwest to northeast. The assumption for the NEP favors most of the eastern German states (except Mecklenburg-Vorpommern), but also Lower Saxony-Bremen. Compared to distribution by potential, the distribution key with social indicators places greater emphasis on eastern German regions, especially Saxony-Anhalt and Brandenburg. There are hardly any differences for North Rhine-Westphalia, although this federal state benefits slightly from a distribution according to social criteria in comparison. The entire south and southwest have a comparative advantage in a distribution by RE potentials. The spatial deviation pattern is almost the same in scenario I and scenario VI.

The second extension of the modelling was the analysis of the impact of regional additional demands triggered by investment. The allocation of additional demand from RE investment in scenario $\mathrm{VI}$ compared to scenario I, both with resource potential distribution, was estimated by processing the regional input-output model and by refeeding results into the macroeconomic projection. The demand is redistributed to the north and southern regions of the east. This is due to the spatial focus of expansion in these regions. In addition, however, it is also noticeable that the manufacturers of wind turbines and PV 
modules are located in these regions. Parts of this pattern can also be found in the studies on the jobs of renewable energy expansion, for which the same model was used (Ulrich \& Lehr 2018). From these studies, it was also deduced that in principle all regions benefit from the expansion, regardless of the location of the plants. However, the relative importance for the overall economy is particularly high in the regions marked with the green buttons in Fig. 9.

\section{Discussion And Conclusions}

This paper compares socioeconomic results under different energy transition strategies. For this analysis, ten existing scenarios were selected, harmonized, and remodeled in an energy system model. Two basic targets of $\mathrm{CO} 2$ reduction ( $80 \%$ and $95 \%$ ) group the ten scenarios, which represent very different strategies with respect to the future technology and energy carrier mix.

The comparison employs a macroeconometric simulation model framework in combination with regional top-down and bottom-up approaches, addressing regional distribution effects and thus the social sustainability dimension in new detail. Another aspect is the almost complete substitution of fossil fuels in the energy system - a regime that has not yet been extensively analyzed in studies up to 2030 or 2040 . The majority of the $95 \%$ scenarios assume a high importance of synthetic fuels, and some see increasing energy imports. The process of import substitution through the expansion of RE is partly phased out approaching 2050. This is reflected in the trade balances under different scenarios.

On the national level, the comparison of different, long-term target scenarios, exhibits patterns which are often found in macroeconomic analysis of the energy transition to date. Investments are decisive and dominant, prices and imports less so. Differences among the more ambitious scenario towards 95\% CO2 reduction are higher than among the $80 \%$-scenarios. In summary, the pathways of GDP and employment are not differing largely. Furthermore, an ambitious approach up to 2050 tends to have a positive effect on the variables, overall, results are in line with similar studies for Germany.

The modeling approach takes several relevant aspects of a sustainability analysis of the outcomes of energy transitions further, however, some important aspects of the transformation have had to be sacrificed for the sake of harmonized scenarios. In particular, the scenarios do not differ with regard to energy efficiency or system costs in transport. Even though mechanisms und structures of an increasing use of hydrogen and synthetic fuels are implemented in the model, only weak assumption could be made about prices (relation development) of these fuels. From an overall national macroeconomic perspective, there will be no regret no matter which transformation path is taken, and due to the harmonization, differences between GDP-development among the very ambitious scenarios are underestimated.

The claim of the deeply disaggregated and empirically based model is to map the future on current behavior and trends by econometric analyses. However, disruptive transitions cannot be foreseen based on past behavior. To simulate new technological pathways, the combination of data driven empirical modeling and energy system modeling accompanied by intensive technical discussions on specific scenarios is necessary for sound results. 
Assessing regional impacts needs a debate on future regional distribution of new energy production capacities and thus investment. When comparing regional developments across the ten scenarios, the differences are low, but still larger than on the national level. The north/east-to-southwest divide often identified in energy transition impact assessment changes to a more complex pattern when only transformation scenarios are compared. Regions have different structures and preconditions that are reflected as regionally differentiated effects in the context of transformation paths. However, it is not only structures but also industry-specific dynamics and development contexts that determine the regionspecific developments.

The combination of the energy system model with the national and regional economic models leads to a more comprehensive picture of growth employment and distribution effects. To further complete this, data on regional value added and interregional trade could strengthen the results.

\section{Declarations}

\section{Ethics approval and consent to participate}

Not applicable.

\section{Consent for publication}

Not applicable.

\section{Availability of data and materials}

The datasets generated and/or analyzed during the current study are available on https://www.innosysprojekt.de, accessed on 12 August 2021.

\section{Competing interests}

The authors declare that they have no competing interests.

\section{Funding}

This research was funded by the German Federal Ministry for Economic Affairs and Energy (BMWi) under the project number 03ET4058 as part of the project InNOSys-Integrated Sustainability Assessment and Optimization of Energy Systems.

\section{Authors' contribution}

Conception, P.U., L.B., U.L.; acquisition, T.N., U.L., analysis, P.U., L.B., U.L., S.S., C.S. interpretation of data, P.U., T.N., U.L.; writing original draft, P.U., L.B. , S.S., C.S.; writing - review and editing, U.L., A.W.

\section{Acknowledgements}


The authors would like to thank Jens Buchgeister, Wolfgang Hauser, Heidi Hottenroth, Tobias Junne, Oliver Scheel, Ricarda Schmidt-Scheele, Ingela Tietze and Tobias Viere for and their repeated contribution to the discussion and their feedback on our results.

\section{References}

AEE (2021): Bundesländer-Übersicht zu Erneuerbaren Energien. https://www.foederalerneuerbar.de/uebersicht/bundeslaender/

AGEB (2021a): Energy Balance for the Federal Republic of Germany 2019.

AGEB (2021b): Satellite balance for renewable energy refering to the Energy Balance for the Federal Republic of Germany.

Bach, S., Isaak, N., Kemfert, C., Kunert, U., Schill, W.-P., Schmalz, S., Wägner, N., Zaklan, A. (2019): CO2Bepreisung im Wärme- und Verkehrssektor: Diskussion von Wirkungen und alternativen Entlastungsoptionen. DIW Berlin: Politikberatung kompakt, No. 140.

BMWi (2021): Zahlen und Fakten: Energiedaten - Nationale und internationale Entwicklung.

Bründlinger, T., König, J., Frank, O., Gründig, D., Jugel, C., Kraft, P., Krieger, O., Mischinger, S., Prein, P., Seidl, H. et al. (2018): Dena-Leitstudie integrierte Energiewende. EWI Energy Research and Scenarios gGmbH: Berlin, Germany.

Destatis (2008): Klassifikation der Wirtschaftszweige.

Destatis (2021): VGR des Bundes - Input-Output-Rechnung - Fachserie 18 Reihe 2.

European Commission (2021): A European Green Deal - Striving to be the first climate-neutral continent. https://ec.europa.eu/info/strategy/priorities-2019-2024/european-green-deal_en

Federal Institute for Research on Building, Urban Affairs and Spatial development (2018): Indikatoren und Karten zur Raum- und Stadtentwicklung. INKAR. Ausgabe 2018. Hrsg.: Bundesinstitut für Bau-, Stadt- und Raumforschung (BBSR) im Bundesamt für Bauwesen und Raumordnung (BBR) - Bonn, Germany.

Federal Ministry for Economic Affairs and Energy (2018): Der Bergbau in der Bundesrepublik Deutschland - Bergwirtschaft und Statistik 2016.

Fragkos, P., Tasios, N., Paroussos, L., Capros, P., Tsani, S. (2017): Energy system impacts and policy implications of the European Intended Nationally Determined Contribution and low-carbon pathway to 2050. Energy Policy 100, pp. 216-226. https://doi.org/10.1016/j.enpol.2016.10.023.

Fragkos, P., van Soest, H. L., Schaeffer, R., Reedman, L., Köberle, A. C., Macaluso, N., Evangelopoulou, S., De Vita, A., Sha, F., Qimin, C., Kejun, J., Mathur, R., Shekhar, S., Dewi, R. G., Herran Diego, S., Oshiro, K., 
Fujimori, S., Park, C., Safonov, G., lyer, G. (2020): Energy system transitions and low-carbon pathways in Australia, Brazil, Canada, China, EU-28, India, Indonesia, Japan, Republic of Korea, Russia and the United States. Energy 216, 119385, https://doi.org/10.1016/j.energy.2020.119385.

German Federal Government (2021): Climate Change Act 2021 - Intergenerational contract for the climate. https://www.bundesregierung.de/breg-de/themen/klimaschutz/climate-change-act-20211936846

Gielen, D., Miketa, A., Gorini, R., Carvajal, P. (2021): 18 energy transition scenarios to watch: where they agree and disagree. https://energypost.eu/18-energy-transition-scenarios-to-watch-where-they-agree-anddisagree/ [accessed 07/26/2021].

Günther, J., Lehmann, H., Lorenz, U., Purr, K. (2017): Den Weg zu einem treibhausgasneutralen Deutschland ressourcenschonend gestalten. German Environment Agency (Umweltbundesamt-UBA): Dessau-Roßlau, Germany.

Hansen, K., Vad Mathiesen, B., Ridjan Skov, I. (2019): Full energy system transition towards 100\% renewable energy in Germany in 2050. Renew. Sustain. Energy Rev. 102, pp. 113. https://doi.org/10.1016/j.rser.2018.11.038.

Henning, H.-M., Palzer, A. (2015): Was Kostet die Energiewende? Wege zur Transformation des Deutschen Energiesystems bis 2050. FhG ISE: Freiburg, Germany.

Klein, S., Klein, S.W., Steinert, T., Fricke, A., Peschel, D. (2017): Erneuerbare Gase-Ein Systemupdate der Energiewende. Enervis Energy Advisors gmBH, Initiative Erdgasspeicher e.V. (INES), Bundesverband Windenergie e.V. (BWE): Berlin, Germany.

Krey, V., Guo, F., Kolp, P., Zhou, W., Schaeffer, R., Awasthy, A., Bertram, C., de Boer, H.-S., et al. (2019): Looking under the hood: A comparison of techno-economic assumptions across national and global integrated assessment models. Energy 172, pp. 1254-

1267. https://doi.org/10.1016/j.energy.2018.12.131.

Lehr, U., Becker, L., Ulrich, P. (2020): Zur Integration strombasierter Energieträger in die Energiebilanz Deutschlands. Energiewirtschaftliche Tagesfragen 11/2020, S. 59-62.

Lehr, U., Lutz, C., Edler, D. (2012): Green Jobs? Economic Impacts of Renewable Energy in Germany. Energy Policy, 47, pp. 358-364. https://doi.org/10.1016/j.enpol.2012.04.076.

Lutz, C., Banning, M., Ahmann, L., Flaute, M. (2021b): Energy efficiency and rebound effects in German industry - evidence from macroeconometric modeling, Economic Systems Research, DOI: 10.1080/09535314.2021.1937953.

Lutz, C., Becker, L., Kemmler, A. (2021a): Socioeconomic Effects of Ambitious Climate Mitigation Policies in Germany. Sustainability 13, 6247, https://doi.org/10.3390/su13116247. 
Lutz, C., Flaute, M., Lehr, U., Kemmler, A., Kirchner, A., Auf der Maur, A., Ziegenhagen, I., Wünsch, M., Koziel, S., Piégsa, A. et al. (2018): Gesamtwirtschaftliche Effekte der Energiewende. GWS, DLR, Prognos, DIW Berlin, Germany; Osnabrück, Germany.

Maier, T., Mönnig, A., Zika, G. (2015): Labour demand in Germany by industrial sector, occupational field and qualification until 2025 - model calculations using the IAB/INFORGE model. In: Economic Systems Research 27(1), pp. 19-42. DOI: 10.1080/09535314.2014.997678.

Naegler, T., Becker, L., Buchgeister, J., Hauser, W., Hottenroth, H., Junne, T., Lehr, U., Scheel, O., SchmidtScheele, R., Simon, S., Sutardhio, C., Tietze, I., Ulrich, P., Viere, T., Weidlich, A. (2021): Integrated Multidimensional Sustainability Assessment of Energy System Transformation Pathways. Sustainability 13, 5217. https://doi.org/10.3390/su13095217

Naegler, T., Weidlich, A., Sutardhio, C., Pregger, T. (submitted): Exploring long-term strategies for the German Energy Transition-A Review of Multi-Sector Energy Scenarios. Renew. Sustain. Energy Transit.

Nieto, J., Carpintero, Ó., Lobejón, L. F., Miguel, L. J. (2020): An ecological macroeconomics model: The energy transition in the EU. Energy Policy 145, 111726. https://doi.org/10.1016/j.enpol.2020.111726.

Nitsch, J. (2014): GROKO II-Szenarien der Deutschen Energieversorgung auf der Basis des EEGGesetzentwurfs-Insbesondere Auswirkungen auf den Wärmesektor. Bundesverband Erneuerbare Energie e.V. (BEE): Stuttgart, Germany.

Nitsch, J., Pregger, T., Naegler, T., Heide, D., de Tena, D.L., Trieb, F., Scholz, Y., Nienhaus, K., Gerhardt, N., Sterner, M. et al. (2012): Langfristszenarien und Strategien für den Ausbau der Erneuerbaren Energien in Deutschland bei Berücksichtigung der Entwicklung in Europa und Global. DLR, FhG IWES, IFNE: Stuttgart, Germany; Kassel, Germany; Teltow, Germany.

O’Sullivan, M., Edler, D. (2020): Gross Employment Effects in the Renewable Energy Industry in Germany An Input-Output Analysis from 2000 to 2018. Sustainability 12(15), 6163.

https://doi.org/10.3390/su12156163.

Oei, P.-Y., Hermann, H., Herpich, P., Holtemöller, O., Lünenbürger, B., Schult, C. (2020): Coal phase-out in Germany - Implications and policies for affected regions. Energy 196, 117004.

https://doi.org/10.1016/j.energy.2020.117004.

Pfluger, B., Tersteegen, B., Franke, B., Bernath, C., Boßmann, T., Deac, G., Elsland, R., Fleiter, T., Kühn, A., Ragwitz, M. et al. (2017): Langfristszenarien für die Transformation des Energiesystems in Deutschland. FhG ISI, Consentec, Ifeu, Karlsruhe, Germany; Aachen, Germany; Heidelberg, Germany.

Pregger, T., Naegler, T., Weimer-Jehle, W., Prehofer, S., Hauser, W. (2020): Moving towards socio-technical scenarios of the German energy transition-Lessons learned from integrated energy scenario building. Clim. Chang., 162, pp. 1743-1762. https://doi.org/10.1007/s10584-019-02598-0. 
Qussous, R., Künzel, T., Weidlich, A. (2019): Effects of a Coal Phase-Out on Market Dynamics: Results from a Simulation Model for Germany. In Proceedings of the 16th International Conference on the European Energy Market (EEM), Ljubljana, Slovenia, 18-20 September 2019.

Repenning, J., Emele, L., Blanck, R., Böttcher, H., Dehoust, G., Förster, H., Greiner, B., Harthan, R., Henneberg, K., Hermann, H. et al. (2015): Klimaschutzszenario 2050-2. Endbericht. Öko-Institut, FhG ISI, HansJoachim Ziesing: Berlin, Germany; Karlsruhe, Germany.

Rocco, M. V., Rady, Y., Colombo, E. (2018): Soft-linking bottom-up energy models with top-down inputoutput models to assess the environmental impact of future energy scenarios. Modelling, Measurement and Control C 79(3), pp. 103-110. https://doi.org/10.18280/mmc_c.790307.

Samadi, S., Terrapon-Pfaff, J., Lechtenböhmer, S., Knoop, K. (2018): Long-term low greenhouse gas emission development strategies for achieving the $1.5^{\circ} \mathrm{C}$ target - insights from a comparison of German bottom-up energy scenarios. Carbon Management 9(5), pp. 549562. https://doi.org/10.1080/17583004.2018.1475174.

Schlenzig, C. (1999): Energy planning and environmental management with the information and decision support system MESAP. Int. J. Glob. Energy Issues, 12, pp. 8191. https://doi.org/10.1504/IJGEl.1999.000840.

Sievers, L., Breitschopf, B., Pfaff, M., Schaffer, A. (2019): Macroeconomic impact of the German energy transition and its distribution by sectors and regions. Ecological Economics 160, pp. 191204. https://doi.org/10.1016/j.ecolecon.2019.02.017.

Übertragungsnetzbetreiber (2019). Netzentwicklungsplan Strom. Szenariorahmen für den Netzentwicklungsplan Strom 2030.

Ulrich, P. \& Wolter, M. I. (2013): LÄNDER-Modell 2013 - Grundlagen, Ansätze und erste Analysen zum aktuellen Modell. GWS Discussion Paper 13/6, Osnabrück.

Ulrich, P. (2013): Regionalisierung indirekter Effekte unter Verwendung nationaler Input-Output-Tabellen und eines räumlichen Allokationsmodells. In: IWH [Hrsg.]: Neuere Anwendungsfelder der Input-OutputAnalyse, Tagungsband. Beiträge zum Halleschen Input-Output-Workshop 2012, Halle, S. 223-238

Ulrich, P., Distelkamp, M., Lehr, U. (2012): Employment Effects of Renewable Energy Expansion on a Regional Level - First Results of a Model-Based Approach for Germany. Sustainability 4(2), pp. 227243. http://doi.org/10.3390/su4020227.

Ulrich, P., Lehr, U. (2013): Erneuerbar beschäftigt in den Bundesländern! Bericht zur aktualisierten Abschätzung der Bruttobeschäftigung 2012 in den Bundesländern. Studie im Auftrag des Bundesministeriums für Umwelt, Naturschutz und Reaktorsicherheit, Osnabrück. 
Ulrich, P., Lehr, U. (2018): Erneuerbar beschäftigt in den Bundesländern - Bericht zur aktualisierten Abschätzung der Bruttobeschäftigung 2016 in den Bundesländern. GWS Research Report 2018/2, Osnabrück.

Ulrich, P., Lehr, U., Lutz, C. (2018): Gesamtwirtschaftliche Effekte der Energiewende in den Bundesländern - Methodische Ansätze und Ergebnisse. GWS Research Report 2018/5, Osnabrück.

Vrontisi, Z., Fragkiadakis, K., Kannavou, M., Capros, P. (2019): Energy system transition and macroeconomic impacts of a European decarbonization action towards a below $2{ }^{\circ} \mathrm{C}$ climate stabilization. Climate Change 162, pp. 1857-1875. https://doi.org/10.1007/s10584-019-02440-7.

\section{Figures}

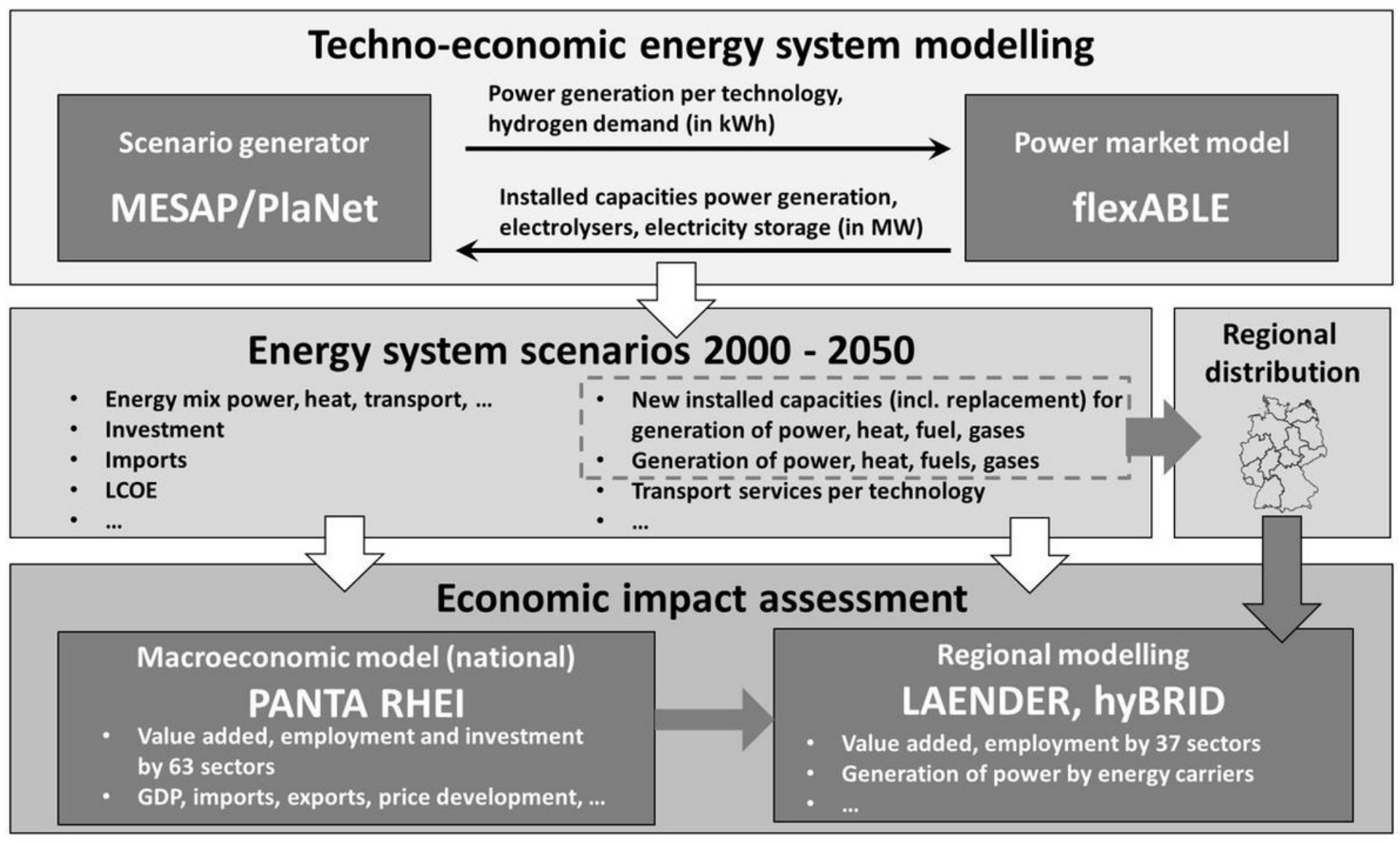

\section{Figure 1}

Overview of the workflow and the model interactions at the national and regional levels as well as key indicators. 
Wind onshore

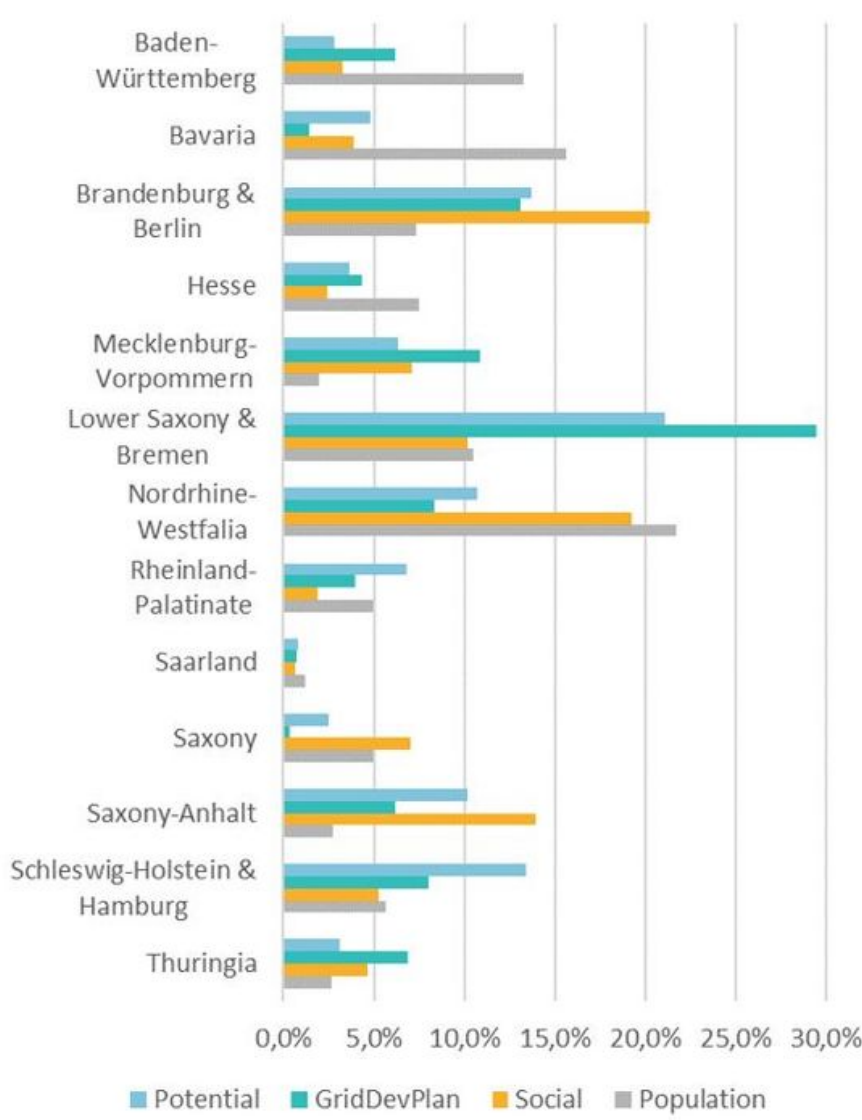

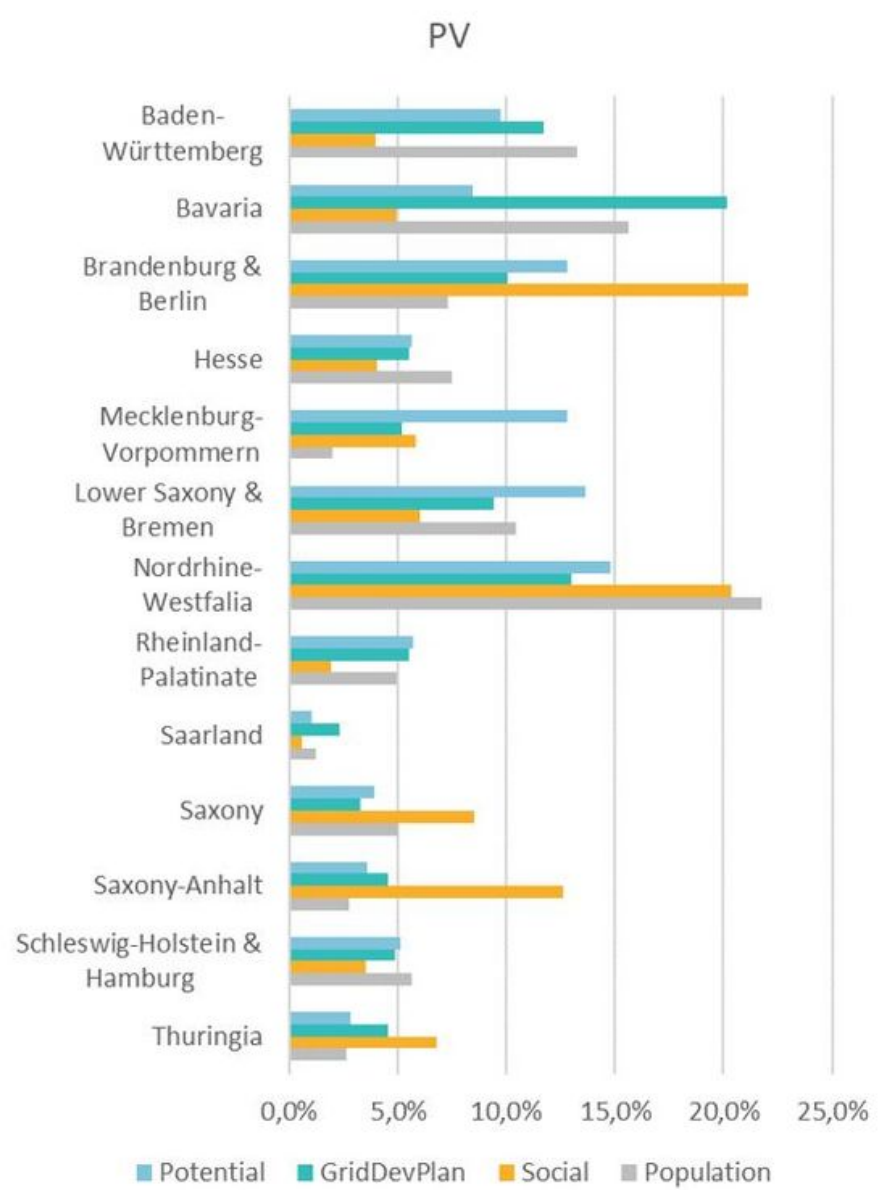

Figure 2

Distribution of newly installed capacities up to 2050 along the regions
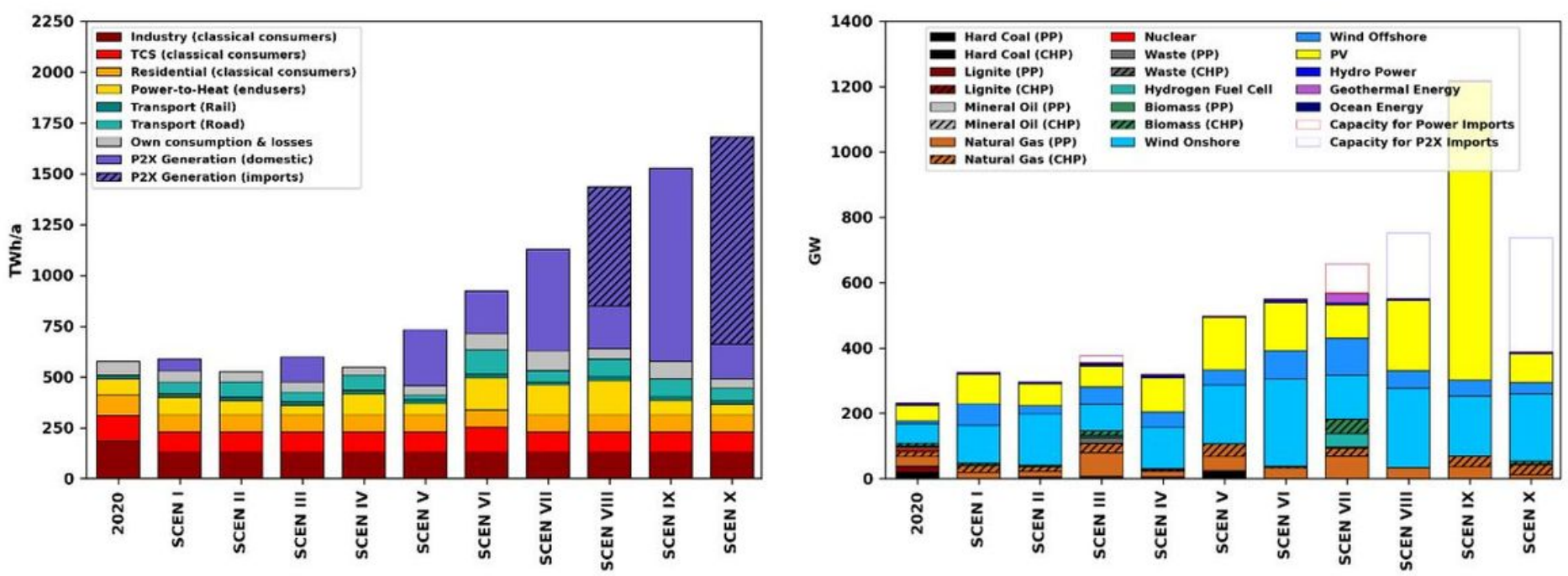

Figure 3

Left Panel: Comparison of gross power demand per application sector (including power demand for P2X imports) in 2050 in all scenarios and comparison with statistical data for 2020; Right Panel: Comparison 
of the installed capacity for power generation per technology/energy carrier in 2050 in all scenarios as well as statistical data for 2020. Note that also power generation capacities for net power imports and for imports of synthetic fuels and gases (P2X) are shown.

(a) gross imports

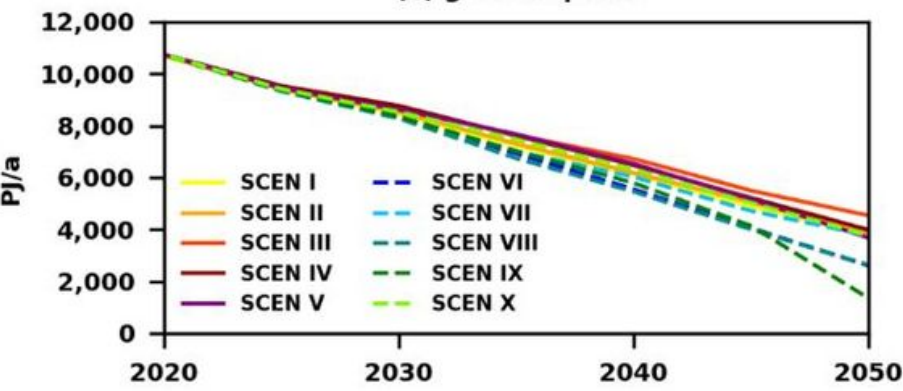

(c) $\mathrm{CO}_{2}$ emissions relative to 1990

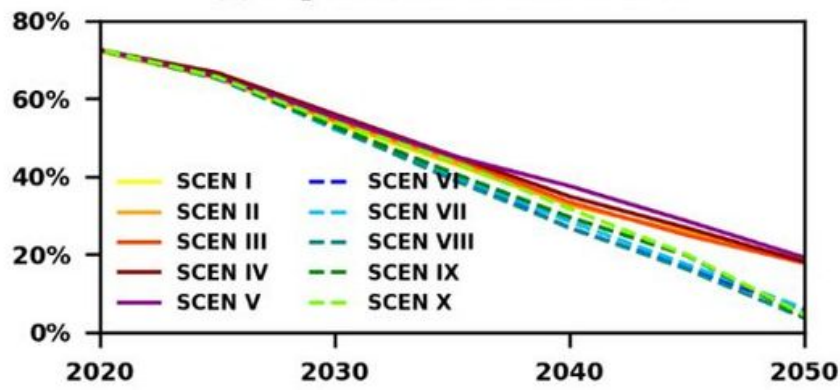

(e) power demand for $P 2 X$

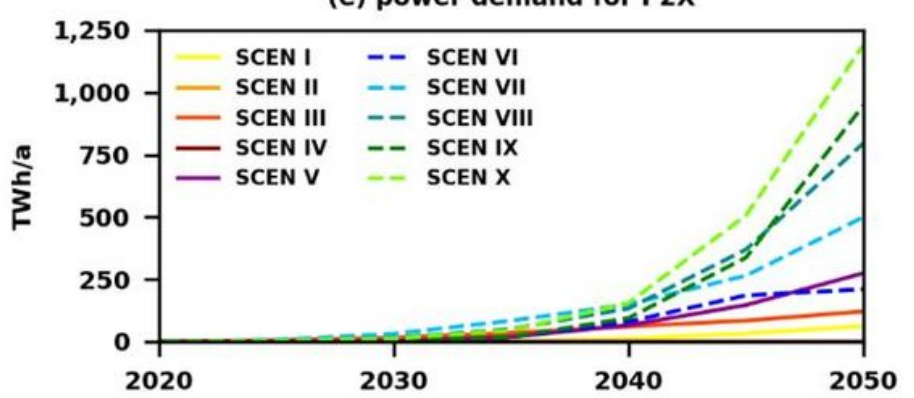

(b) annual capital costs

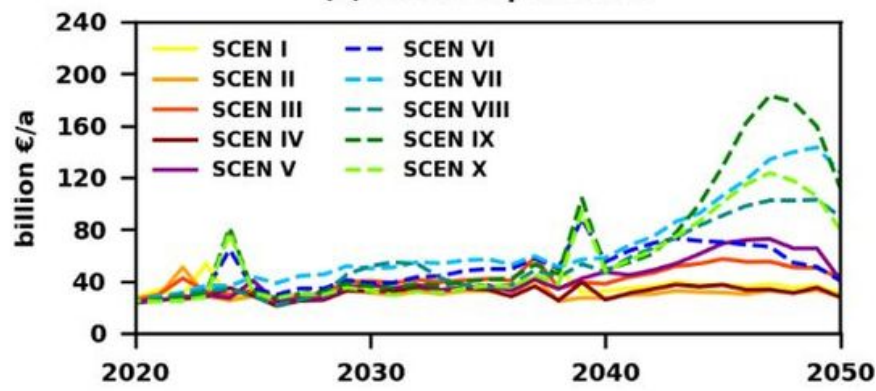

(d) annual $O \& M$ costs

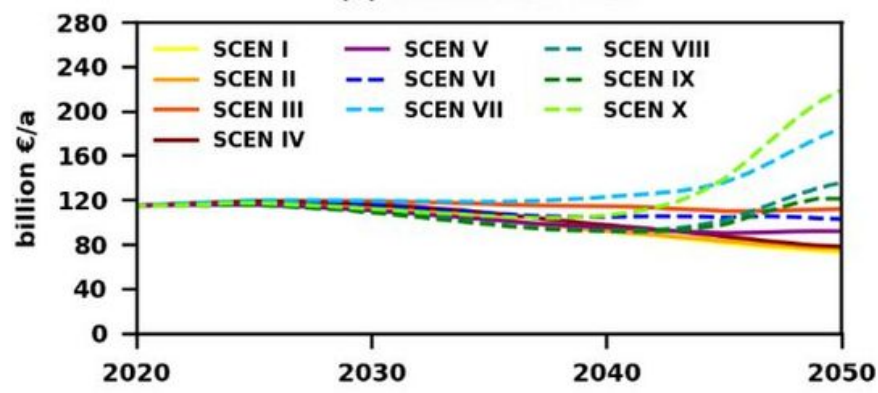

(f) annual system costs

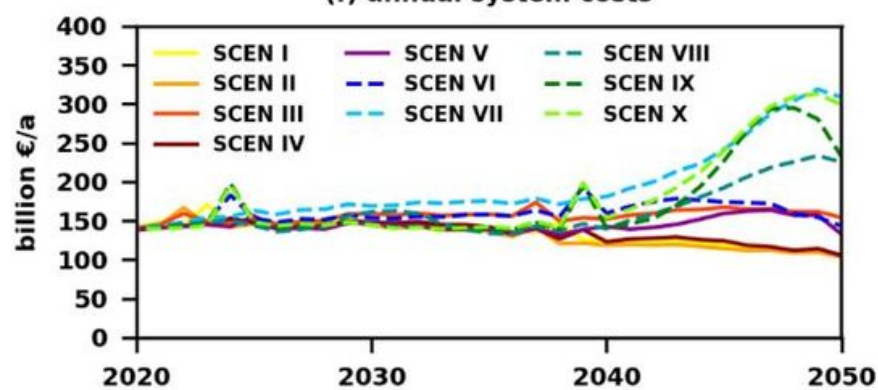

Figure 4

Comparison of results for all ten scenarios: (a) gross imports of energy carriers (in PJ/a); (b) annual capital costs (annuities); (c) CO2 emissions relative to 1990; (d) annual O\&M costs; (e) power demand for $\mathrm{P} 2 \mathrm{X}$ generation (including power demand for P2X imports); (f) total system costs (= capital costs + O\&M costs) 


\begin{tabular}{|c|c|c|c|c|c|c|}
\hline \multirow[b]{3}{*}{ Scenario } & GDP & $\begin{array}{l}\text { Investment, } \\
\text { Construction }\end{array}$ & $\begin{array}{c}\text { Investment, } \\
\text { Equipment }\end{array}$ & Imports & \multirow{2}{*}{$\begin{array}{c}\begin{array}{c}\text { Consumer } \\
\text { Price Index }\end{array} \\
2015=100\end{array}$} & \multirow{2}{*}{$\begin{array}{c}\text { Employment } \\
1000\end{array}$} \\
\hline & \multicolumn{4}{|c|}{ price-adjusted, Bn Euro } & & \\
\hline & \multicolumn{6}{|c|}{ Average of the years 2030 to 2050} \\
\hline Scen I & 3752 & 275 & 545 & 2729 & 147.9 & 43880 \\
\hline Scen II & 3749 & 273 & 542 & 2724 & 147.8 & 43870 \\
\hline Scen III & 3756 & 276 & 549 & 2730 & 148.0 & 43888 \\
\hline Scen IV & 3749 & 275 & 542 & 2724 & 147.4 & 43890 \\
\hline Scen V & 3757 & 280 & 556 & 2740 & 147.7 & 43936 \\
\hline Scen VI & 3775 & 285 & 558 & 2736 & 147.8 & 43983 \\
\hline Scen VII & 3788 & 292 & 571 & 2753 & 148.3 & 44009 \\
\hline Scen VIII & 3762 & 281 & 553 & 2735 & 148.0 & 43946 \\
\hline Scen IX & 3784 & 295 & 576 & 2762 & 147.6 & 44048 \\
\hline Scen X & 3744 & 276 & 546 & 2734 & 147.8 & 43875 \\
\hline
\end{tabular}

\section{Figure 5}

Simulation results of the macroeconomic model PANTA RHEl for selected economic indicators, averages for the period 2030-2050. See also Naegler et al. (2021) for further indicators. 


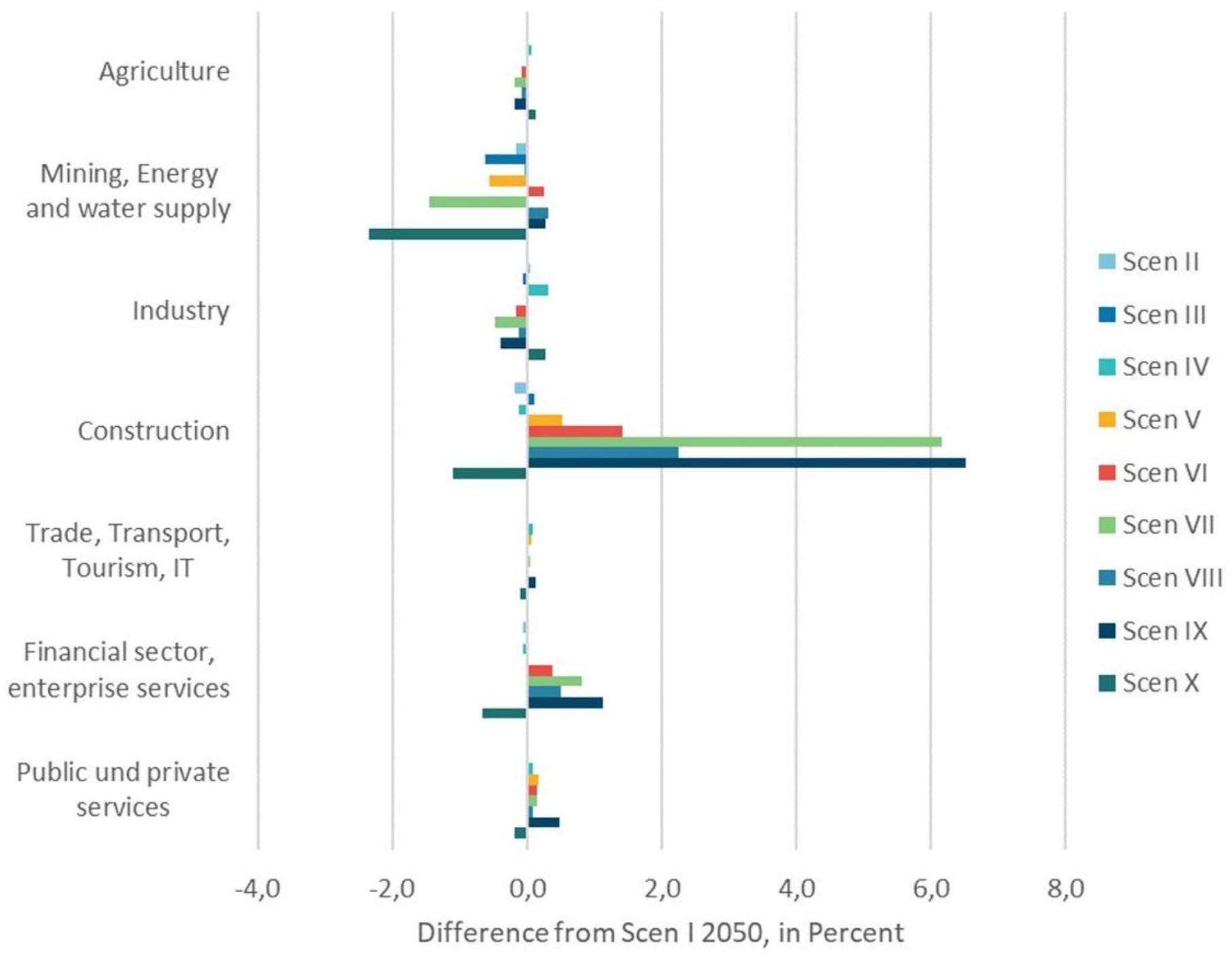

Figure 6

Employment in selected economic sectors, relative differences of 9 scenarios compared to Scen I, based on Naegler et al. (2021) 


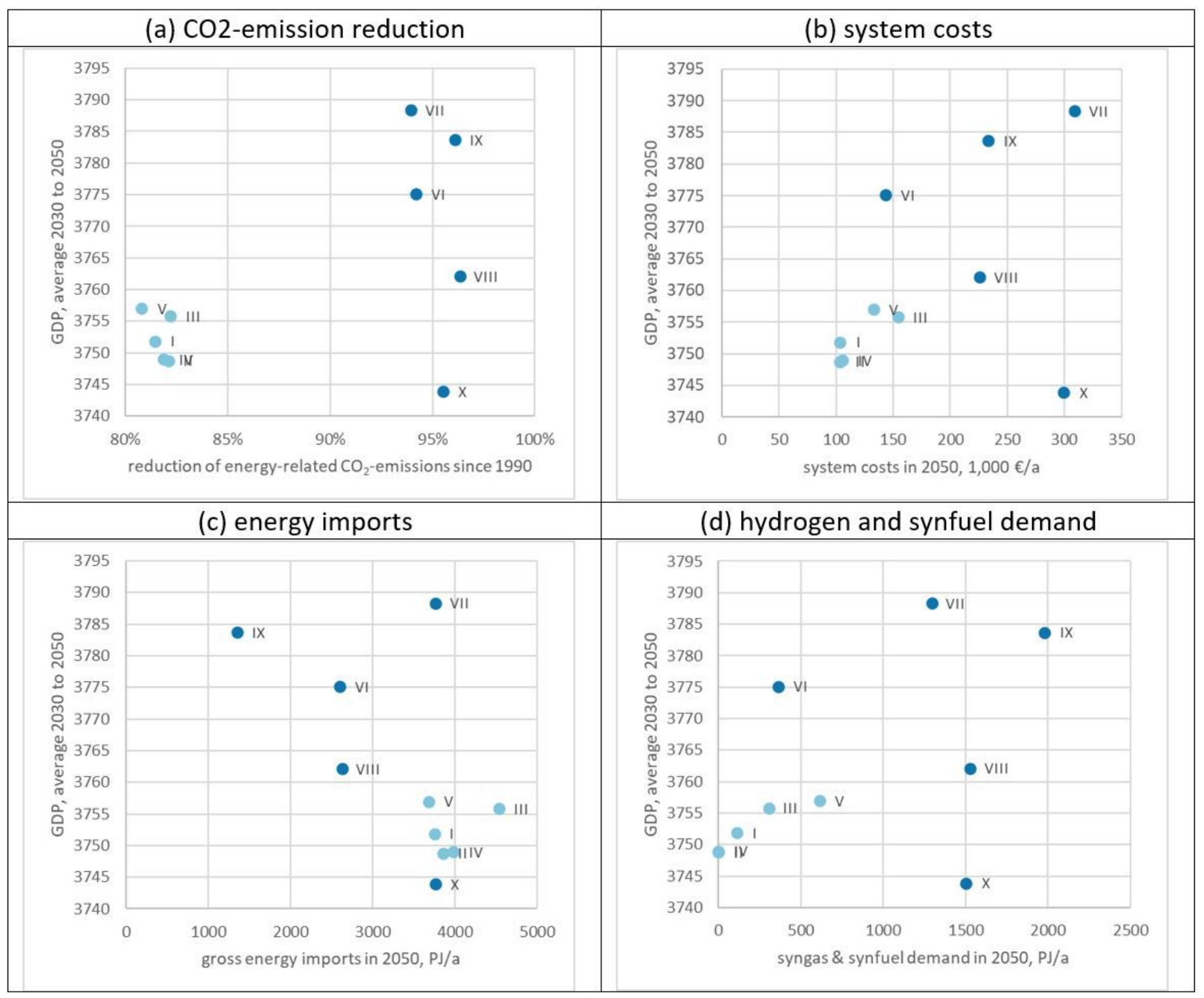

\section{Figure 7}

Comparison of realizations for GDP in 2050 with indicators from energy system modeling. 


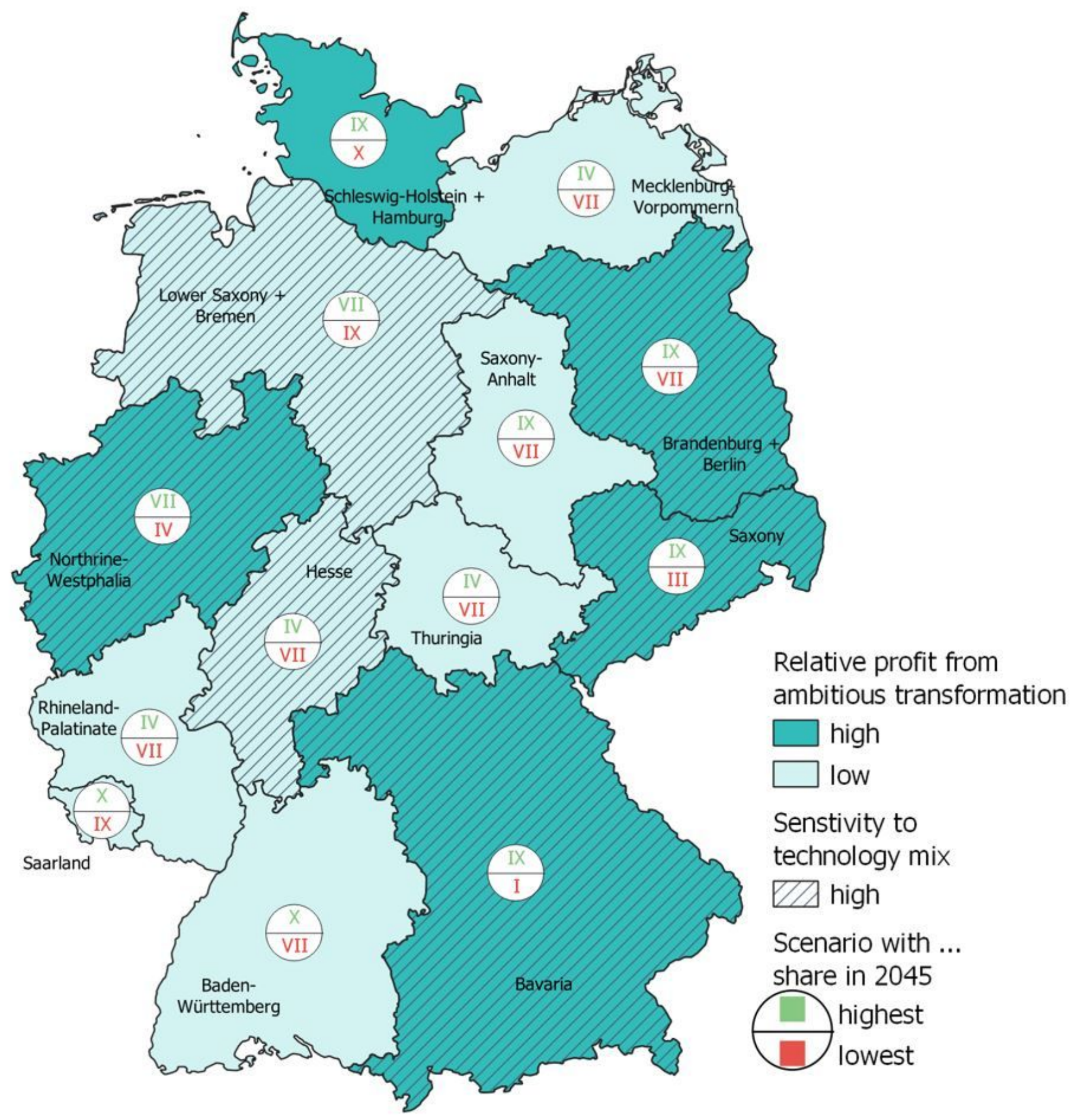

Figure 8

Clustering of regional effects for 13 major regions in 2045 


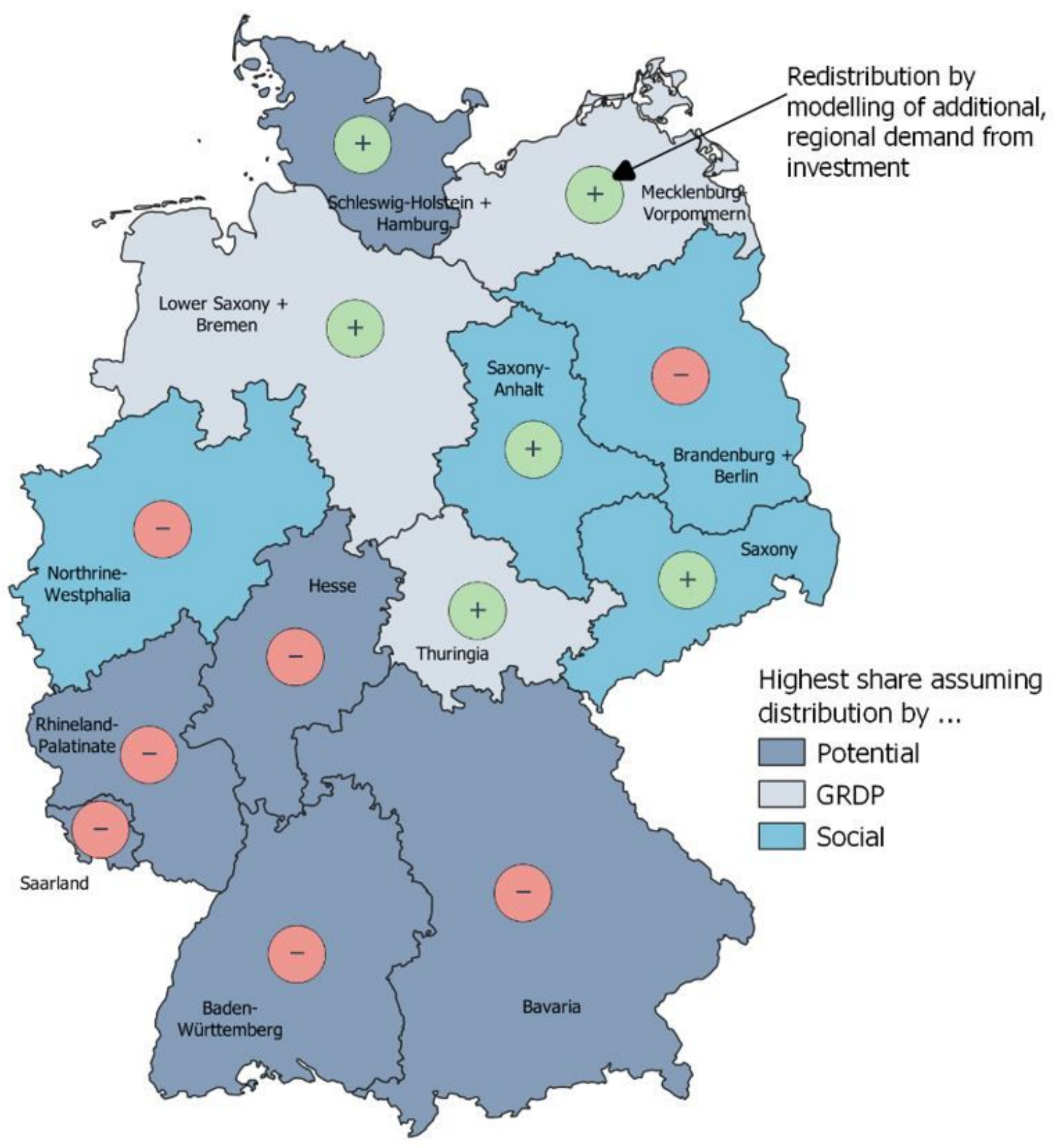

Figure 9

Results of the spatial sensitivity analysis - the most advantageous distribution for the regions and aspects of local demand by investment

\section{Supplementary Files}


This is a list of supplementary files associated with this preprint. Click to download.

- UlrichetalAssessmentofeconomicimpactsESSsupplement.docx 